\title{
norden
}

Nordic Council of Ministers

Ved Stranden 18

DK-1061 Copenhagen K

www.norden.org

NORDISKE ARBEJDSPAPIRER

NORDIC WORKING PAPERS

\section{Interviews with students on the Nordic Master Programme}

Anniina Pirttimaa

NA2013:901

http://dx.doi.org/10.6027/NA2013-901

This working paper has been published with financial support from the Nordic Council of Ministers. However, the contents of this working paper do not necessarily reflect the views, policies or recommendations of the Nordic Council of Ministers. 


\section{Content}

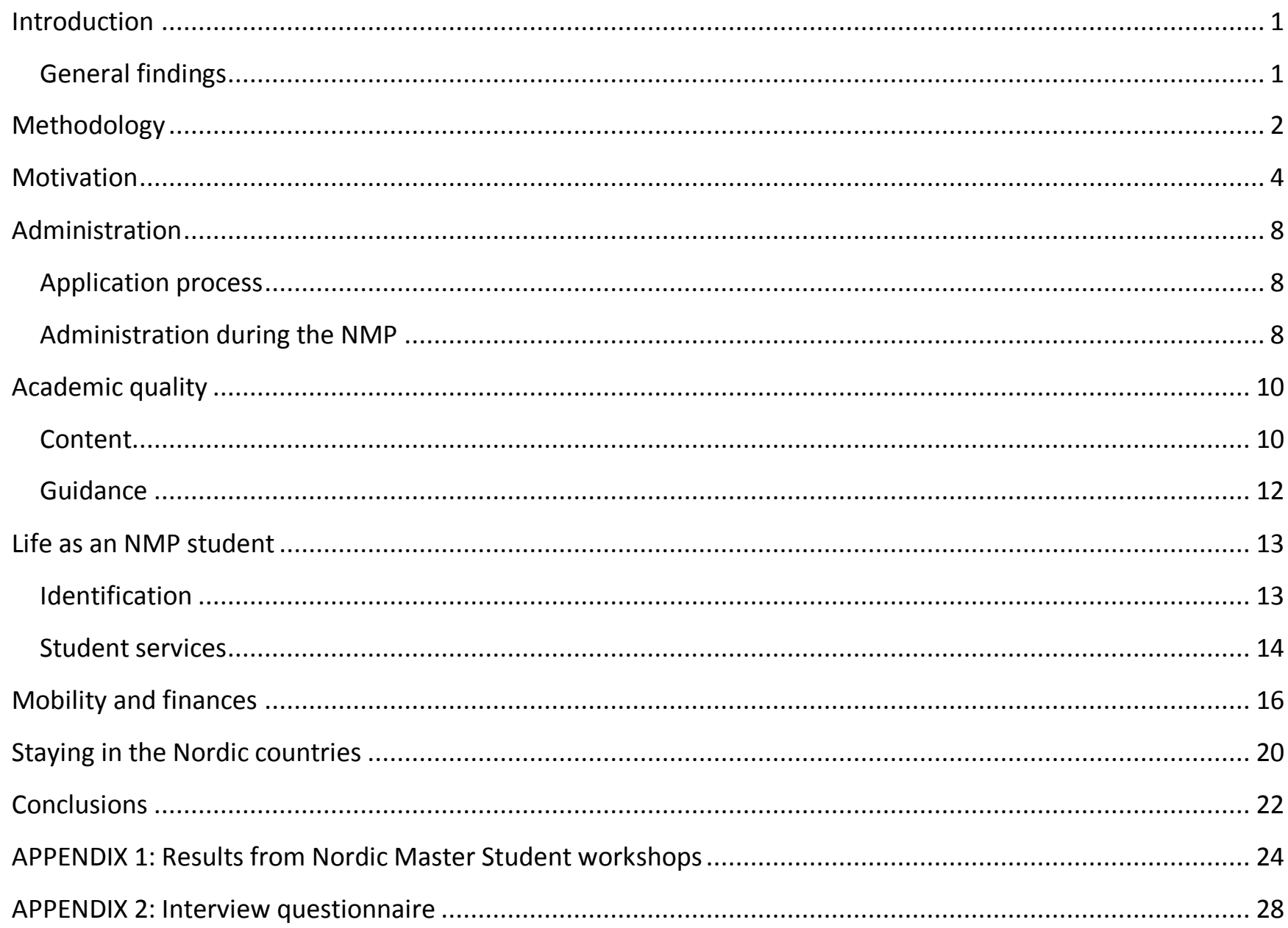




\section{Introduction}

The Nordic Master Programme (NMP) is an initiative launched by the Nordic Council of Ministers with the purpose of creating new types of Master's programmes in the Nordic countries. From the first call for proposals in 2007 up until the spring of 2012, nine programmes with up to 200 enrolled students were launched by close to 20 collaborating Nordic universities.

In order to gain a deeper understanding of the students' experiences of the NMP, the working committee convened by the Nordic Council of Ministers to evaluate the initiative decided in April 2012 to launch a study focusing on the student perspective. The study was conducted on the basis of both an online survey sent out to all enrolled and graduated students on the Nordic Master Programme, and longer interviews with selected students from all participating programmes. Therefore, this report - which presents the conclusions from the student interviews - should be read in parallel with the results from the Nordic Master Student Survey 2012, which was sent out as an online questionnaire to all enrolled and graduated NMP students in May 2012. The findings from the interviews presented in this report will be used alongside the statistical findings from the online survey, and conclusions will be drawn wherever possible. The findings will be used in the overall evaluation of the Nordic Master initiative.

\section{General findings}

Both in the online survey and the student interviews, the students express a very high level of satisfaction with the NMP - up to $96 \%$ of respondents to the survey report that they are satisfied or very satisfied with the programme. Up to $99 \%$ of the students would also recommend the programme to others. These results are very similar to the experiences of the students who were interviewed, nearly all of whom said that they would recommend the programme to others and happily decide to do the NMP all over again. However, during the interviews, students also pointed out many practical issues with the NMP that still need to be resolved. Many of these issues are related to administration, but also concern the structure of the NMP and questions of mobility. Students also frequently point out the importance of support, in the form of academic, administrative and professional guidance. All of these issues will be addressed more closely in the following chapters. 


\section{Methodology}

All current Nordic Master Programmes were requested to nominate two or three students per programme for the interviews conducted by the Secretariat of the Nordic Council of Ministers. In order to guarantee a broad representation of different geographical backgrounds, the programme co-ordinators were instructed to nominate at least one Nordic student and one non-Nordic student where possible. Of the ongoing nine programmes, all but two chose to participate. Up to five students were nominated per programme. In addition, the students themselves were offered the opportunity to volunteer to be interviewed via the online survey. Ultimately, the interviewer was responsible for selecting the interviewees. Where possible, the students were chosen in such a way that all programmes were represented by at least two students - one male and one female - from different geographical backgrounds. In total, 14 NMP students were interviewed. Of these, seven were from Europe (including four from the Nordic countries) and seven were from non-European countries. Of these, nine students were male and five female. Half of the 14 interviewees had already graduated, whereas the other half were at the end of their second year on the Nordic Master Programme.

Table 1: Participants

\begin{tabular}{|l|l|l|l|l|l|}
\hline Programme & Interviews & $\begin{array}{l}\text { Nordic } \\
\text { students }\end{array}$ & $\begin{array}{l}\text { European } \\
\text { students }\end{array}$ & $\begin{array}{l}\text { Non-Eur. } \\
\text { students }\end{array}$ & Graduated \\
\hline $\begin{array}{l}\text { Innovative and Sustainable Energy } \\
\text { Engineering }\end{array}$ & 3 & 0 & 1 & 2 & 1 \\
\hline Marine Ecosystems and Climate & 2 & 1 & 1 & 0 & 1 \\
\hline Gerontology & 2 & 0 & 0 & 2 & 2 \\
\hline Religious Roots of Europe & 2 & 1 & 0 & 1 & 2 \\
\hline $\begin{array}{l}\text { Computational Chemistry and } \\
\text { Physics }\end{array}$ & 2 & 1 & 0 & 1 & 0 \\
\hline Maritime Engineering & 2 & 0 & 1 & 1 & 0 \\
\hline Master in Didactics of Mathematics & 1 & 1 & 0 & 0 & 1 \\
\hline $\begin{array}{l}\text { Innovative Information and } \\
\text { Communication Technologies }\end{array}$ & - & - & - & - & - \\
\hline Plant Pathology & - & - & - & - & - \\
\hline Total & 14 & 4 & 3 & 7 & 7 \\
\hline
\end{tabular}

The interviews were mainly conducted through a teleconference system, which enabled participants around the world to interact naturally with the interviewer. On a few occasions, the interviews were conducted by telephone. The interviews were conducted confidentially. Each student has had the opportunity to review his/her interview report. Each interview lasted approximately one hour and addressed questions related to motivation for applying, the quality of the programme (both administrative and academic), mobility and economic aspects, as well as future career plans. The students were also asked to give an overall evaluation of the programme and comment freely on any matters they wished to address. The questionnaire used in the interviews is similar to the structure of the online survey (see Appendix 1). 
The conclusions presented in this report are based on interpretation of the material. The conclusions will be discussed further at four student workshops in September and October 2012, which are open to all current and former NMP students. The workshop reports will be included in the appendices of this report. 


\section{Motivation}

When asked about the main motivation for applying for the NMP, most students say that their decision was based on a combination of factors. Although the wording may vary and some reasons are more important to some students than others, four main motivators can be identified: mobility, academic quality, good opportunities for networking and lack of tuition fees. The following chapters will address these motivators more closely.

- Mobility. All interviewees say that one of their main reasons for applying was the fact that the NMP offers the opportunity to experience many Nordic institutions and countries. This is also in line with the results from the Student Survey, where $71 \%$ of respondents said they chose the NMP because they liked the idea of studying in several Nordic countries. However, some distinct characteristics can be identified among the students:

Nordic students seem somewhat more attracted by the idea of doing an international degree at home. Most of the Nordic students interviewed had chosen to combine the NMP with a period at their own home institution. This may be due to the fact that, at national level, the NMPs mainly seem to be marketed to Bachelor students who are already studying at the participating institutions. However, some of the Nordic students (as well as other students already living in the Nordic countries) also say that they are or would have been quite satisfied with only studying in their home country, with shorter mobility periods in other countries.

The convenience of staying at their home institution, thereby retaining their own apartments and their existing social surroundings while still being able to add an international element to their studies, was the main reason cited by many Nordic students (or non-Nordic students already living in the Nordic countries) for choosing the NMP. However, these students also recognise the general value of doing a NMP with longer periods abroad, even if that was not necessarily their preferred model.

"It was very attractive to me to get the opportunity to study at all the leading Nordic institutions in my field, and still be living in my home country and stay at my own university." - Nordic NMP Student

Many of the Nordic students interviewed also state that they had not initially intended to do an international Master's or even an exchange period abroad, but once they heard of the existing NMP they decided to pursue a more internationally oriented Master's degree. For these students, the desire to do an international degree was therefore not obvious from the start, but rather arose after they learned about the existence of the NMP. Only in a few cases were students already motivated to pursue an international degree, and were actively looking at opportunities abroad before learning about the NMP. In these cases, the NMP proved to be an attractive option for students who could not find an interesting track in their own country.

Non-Nordic students are, in comparison to Nordic students, more attracted by the opportunity to study at many Nordic institutions and move around in the Nordic countries during their NMP. The fact that the NMP offered the chance to experience many Nordic institutions, countries and cultures is clearly a major selling point for non-Nordic students interested in studying in the Nordic Region. A prior interest in the Nordic countries is also evident among the interviewees, many of whom either have family 
connections in the Nordic countries or have lived or studied previously in the Region. It seems that many of the non-Nordic students had found information about the NMP while looking at national Master's programmes in the Nordic countries. In other words, it is likely that many of the non-Nordic students would have chosen to study at a Nordic institution regardless of the NMP, but considered the NMP more attractive than programmes taught in only one Nordic country. In conclusion, the programmes in the initial phase of the NMP seem to attract students already interested in the Nordic countries.

- Academic quality. When asked about their main reasons for applying for the NMP, nearly all students mention high academic standards, a specific interest in the subject area and opportunities for academic specialisation. The students feel that the NMP could offer a track that was not available through national Master's degrees. The many high-level universities participating in the programme and a great selection of courses are also mentioned as reasons for choosing the NMP. In a few cases, non-Nordic students had even applied for their NMP only because the Nordic countries are at the forefront in a specific field of study. In these cases, the students don't have any significant prior connection to the Nordic countries.

From the interviews, it can be noted that the NMPs seem to attract specialists rather than generalists. The students who apply for the programmes are very goal-orientated and ambitious, with a clear vision of what they want from their studies, and usually already have a strong knowledge base within their own field. Because of this, expectations regarding the academic content are also high, and students are attracted by the idea of specialising even further within a certain field. This might also be because several of the current programmes are designed in such a way as to address a quite narrow field with a very specific focus.

Academic motivation is also one of the main reasons cited in the Student Survey, where $62 \%$ said that they had chosen the NMP since it aligned with the student's educational plans. Similarly, $44 \%$ said that they had chosen the NMP since it fulfilled their high educational ambitions, whereas $23 \%$ indicated that the Nordic Region is a leader within their specific field.

- Good opportunities for networking (in pursuit of PhD or other career options). Improved opportunities for establishing a large network in pursuit of future career options are mentioned as a reason for applying for the NMP by nearly all of the interviewees. This seems to hold especially true for students with PhD ambitions. A clear majority of the students who mention networking as one of the NMP's top benefits also state that they are already actively pursuing a PhD, or felt that they might do so in the future.

Five out of the 14 students interviewed state that doing a PhD was already an explicit goal for them when applying for the NMP. For these students, the NMP was an especially attractive option since it offered the opportunity to study at many well-known Nordic institutions and establish an extensive network. All in all, eight of the 14 said that they are currently pursuing or open to pursuing a PhD. In addition, many of those who are not pursuing a PhD recognise that the NMP offers better possibilities for doing a PhD than national Master's degrees. 
"Doing a PhD was not my goal, but the potential is really good now that l've got to know so many different professors." - European NMP student

The students were asked how they expect to benefit from this network, and it is clear that they believe that contact with many universities will create more opportunities than can be offered by a national programme. The students say that they expect the NMP to add an international dimension to their profile; give students a good overview of which institutes are working on which projects within their field; and make it easier to, for example, get recommendation letters from professors from many top universities when applying for PhD programmes. In some instances, the students had also expected to be more involved in ongoing research while on the Master track. Where these expectations were not met, the students express disappointment in the NMP.

It is worth noting that the NMP's value in establishing a large network is also noted by those students who want to pursue a career outside of academia. Some students even mention that the network established during the NMP had already proven useful in their working life after graduation.

"When I study here I can get more contacts and meet more people, so my chances of having a broad network are bigger. So if in the future I work in a company and they need more people, I will already know people from this programme from all the Nordic countries." - European NMP student

In comparison to the results from the online Student Survey - where only $17 \%$ said that they had chosen the NMP because of better possibilities for receiving a PhD in the Nordic countries - the results indicate that this percentage may in fact be higher among the students who were interviewed. Further, students also seem to mature into the idea of pursuing a PhD during the NMP, even though this may not have been a clear goal to begin with.

- Lack of tuition fees. Among the students interviewed, three of the seven non-European students mention the lack of tuition fees as one of the main reasons for choosing the NMP instead of competing programmes in other countries. This is in line with the results from the online Student Survey, where $31 \%$ of non-European students indicated that tuition fees had been to a high or some degree a factor in choosing the NMP.

During the interviews, the importance of tuition fees (or the lack thereof) also varies between students: some say that the fact that the studies were free from tuition fees was not a determining factor (but rather a pleasant bonus), but for others it was clearly very important.

"To be very frank, I chose the programme because there was no tuition fee. Second, I found the programme structure with many different Nordic institutions interesting."

\section{- Non-European NMP student}

Asked if they would be willing to pay tuition fees for their NMP, several students comment that the Nordic countries are expensive places to live and therefore covering both tuition fees and living costs might be a big challenge. Nevertheless, some students still feel that their NMP experience had been of a sufficiently high quality to potentially justify some fees, but external factors, such as living costs and language barriers on the labour market, still remain problematic. Others were also quite open about that fact that they would not opt for the NMP if tuition fees were charged: 
"If the Nordic Master Programme charged the same kind of tuition fees as the US, I would choose the US." - European NMP student

\section{Alternatives to NMP?}

Of the Nordic students interviewed, only a few state that they had looked at other international programmes. These students were mainly interested in studying in other Nordic countries, or were perhaps only looking for shorter exchange periods abroad in order to improve their language skills (in the case of Nordic students).

While many of the non-Nordic students were specifically interested in the Nordic countries, some state that they had looked at other international Master's programmes too. These students mainly mention Englishspeaking countries such as the UK, US and Canada. The Erasmus Mundus programme is mentioned on one occasion, but in this case the student had concluded that the NMP's academic content was more attractive, even though the Erasmus Mundus programme would have involved more financial support. 


\section{Administration}

Although many of the interviewees have positive experiences related to the administration of the programmes, the majority mention practical issues in connection to the application process or administration in general. The issues mentioned can mainly be divided into ones related specifically to the application process and general administrative issues arising during the programme itself.

\section{Application process}

- Application timeframe. Several students (from different programmes) mention that the deadline for sending in the application for the programme was much earlier than for other Master's programmes (January was frequently mentioned, as opposed to March in many other European programmes), which meant that the application was rushed. In some cases, Nordic students also state that the timeframe for taking the required English language tests was rather pressed.

- Acceptance to the programme. The students' experiences of the acceptance procedure vary to a high degree: while some students received their acceptance letter within weeks, others had to wait for up to five months. In particular, the non-Nordic students comment on the long processing time from sending in the application to being accepted to the programme. In some cases, the students learnt of their acceptance only a month before the semester started, which made it very difficult for them to find accommodation at their new place of study. In addition, delayed acceptance letters have in some cases caused difficulties for students who have applied for scholarships, but have not been able to document their place of study. Students also mention that they had been approached both by employers and by other Master's programmes while waiting to be accepted to the NMP. The long application process was especially frustrating for those who had no clear point of contact for the NMP.

- Entry requirements. In a few selected cases, the students mention unclear entry requirements. Students have found it especially puzzling when institutions within the same NMP have had different entry requirements. In at least one case, this has caused a student to drop out of the programme after one year, when the second-year NMP institution denied the student entry based on their lack of qualifications. This was a great source of confusion not only for the student in question, but for all students participating in that specific NMP.

\section{Administration during the NMP}

- Programme co-ordinator. As mentioned, several of the students found that they were uncertain whom they should contact in the event of questions arising during the application process. This problem seems to persist during the programme. Students do not know whom they should contact regarding administrative matters related to the NMP. In some cases, academic personnel (professors, PhD students) have acted as contact points in this context. However, it seems that this arrangement has not been successful, since students say that in many cases the academic personnel do not always have the time (or even the know-how) to address administrative questions. Many students are keen to point out that the academic counsellor and administrative contact point should not be the same person. Instead, students would prefer one person within the university to handle all NMP administration. With one 
common co-ordinator, it would also be easier to gather together all NMP students who are studying at the same institution, something that several students wish would be easier.

"It was really difficult for us to find out which courses we were supposed to take, since no one ever replies to e-mails." - European NMP student

- Website. While students on some programmes found their websites to be very informative and comprehensive, others feel that the NMP website lacks information regarding either the application process or the programme itself. Instead, to get the latest information, students need to visit the participating institutions' websites separately.

- Bureaucracy. Several students comment on the lack of co-ordination between the administrators of the programme at different institutions. In many cases, the students themselves are also in charge of ensuring that the courses they attend at the different NMP institutions are included in their diploma. This gives the students the impression of a lack of communication between the different universities in the programme. As one student describes the situation:

"That's the biggest problem with the NMP. Since there are two universities, you have to deal with double the bureaucracy." - European NMP student

- Granting of the degree. Some students are unclear as to whether they will receive a single degree from one of their host institutions or if they will get double or joint degrees from all of the institutions. In some instances, there has also been confusion regarding the title of the diploma.

- Sending of diplomas. In some instances, students have waited several months to receive their diplomas after graduation. The participants in the online Student Survey also commented upon this:

"It is appalling that we have not received our final diploma. It is nearly nine months since I graduated, and 11 months for some of my co-students. During some of my job interviews, people found it laughable that we had no official diploma so long after graduation. Unfortunately, this makes a mockery of the programme and is a problem for us (the students) when applying for jobs. I find it very hard to see why this has taken so long!" - Open answer in NMP Student Survey 2012 


\section{Academic quality}

In this section, students were asked to describe and evaluate the academic content of the programmes. While many of the comments are specifically related to the academic content of certain programmes (and as such cannot be seen to apply to all NMPs), some general observations can be made. In addition to commenting on the content, a significant feature of the students' replies is that they frequently mention the need for more guidance and feedback.

\section{Content}

Overall, the vast majority of the students interviewed state that they are very satisfied with the academic content of the programme. This corresponds well with the high ratings in the online survey, where $54 \%$ of the students say that the NMP has to a high degree lived up to their academic expectations, while close to $100 \%$ say they are satisfied with the teaching styles and methods. In the interviews, students are in general very positive about the academic content, and describe it as, for example, "high-standard and even luxurious".

While some interviewees feel that the content of the programmes has been to too great an extent left up to students, others seem to appreciate this freedom. Similarly, students have varying opinions on whether they prefer courses only for NMP students or courses from the general curriculum. The benefits of NMP-only courses include a more specific academic focus and a tighter NMP group, whereas courses for all students mean that the students also have the chance to meet non-NMP students.

Although it is difficult to draw any general conclusions on the quality of the academic content of seven different programmes, some smaller observations can be made.

- Online courses. There seems to be great variation in the provision of online courses by the different partner institutions. Nevertheless, in the interviews, those students who have been offered online courses in addition to contact seminars seem to be quite satisfied with the arrangement, and find it a good way of interacting with students and academic personnel who are on the same NMP programme but located at other institutions. Although the interviewees are rather positive about online courses, respondents to the survey are slightly more critical about e-learning and express a wish for a stronger focus on face-to-face interaction.

- Interactive courses. Many students whose NMP included many group assignments and workshops comment positively on this, and feel it will be a great advantage for them in their professional lives.

"I feel my later professional life will be easier because of this programme." - European NMP student

"The quality of the programme is very high, higher than in my home country. Writing reports and working in teams has been a new experience for me. It has been very useful."

$$
\text { - Non-European NMP student }
$$

- Content of intensive courses. In programmes that include shorter, intensive courses in other Nordic countries, the students seem, in some cases, to question the worth of the courses, particularly if they do not include any added value, such as closer connections to local solutions within the field. One student described the problem like this: 
"Why would you invest in us coming to another Nordic university and just (passively) have us listen to classes all day, when we could have done that at our host university, too?"

- Non-European NMP student

- Cancellation of courses. Students studying at some of the smaller programmes mention that some courses have been cancelled due to too few students signing up.

- Level of English. Most students are satisfied with the level of English in the teaching, but in a few cases, the students feel that, for example, assignments have been worded so poorly that it has caused confusion. Some non-European students also mention that they have initially struggled with their own level of English too.

- More courses in English. Not all NMPs offer all of their courses in English, which makes the selection of courses for non-Nordic students rather limited.

- Summer courses/traineeship. Some of the interviewees express a wish for the opportunity to do courses or a traineeship during the summer months. This is especially the case for non-European students who might not be travelling home during this period.

- Work experience. In addition to strictly academic content, students also repeatedly express a wish to practice their skills in an actual work environment as a part of their NMP. In cases where in-work training is an integral part of the programme, the students greatly appreciate this aspect.

Students feel that a part-time job in connection with their NMP would not only help with their living costs, but also provide them with much-needed work experience. Even unpaid traineeships would be of interest. Students also feel that some in-work training during the NMP would also increase the value of the programme. The main problems when it comes to the students finding jobs are that at the beginning of their studies they don't have the necessary networks for finding a job within their field (something the students feel the programme could help with) and the fact that in many cases it is not possible to combine work with the rather intensive study requirements.

"The studies are quite intensive, so it would be quite difficult to include a traineeship period, but if it would be possible it would probably be quite attractive to the students." - Nordic NMP student

"The summer is a good opportunity to find a job in one of the countries where I will study." - NonEuropean NMP student

"The main thing would be to get experience. Right now I have none." - Non-European NMP student 


\section{Guidance}

In addition to administrative assistance, several students also call for more comprehensive academic guidance. During the interviews, the most satisfied students are often those have had active contact with several professors during the programme and received a lot of academic guidance.

In particular, three areas can be identified as important in the provision of academic guidance:

- Support in designing the NMP. Many of the interviewees feel that they did not receive enough information and guidance when putting together their initial study plan for the NMP. This is especially evident in cases where the students felt rushed when choosing the NMP institution for their second year of study - in some cases, the students had less than a week to make this decision. In comparison, positive experiences from different NMP programmes are often connected to some kind of initial meeting for new students, where the different options within the NMP are presented early on.

- Regular contact with academic personnel. Many students also call for stronger academic guidance during their studies. The level of guidance within NMPs seem to vary considerably: in some programmes, students have had weekly academic guidance sessions with professors or PhD students, while in other programmes the students have had no clear contact point for their academic concerns. Many also feel that they would have benefited from stronger guidance from the professors while writing their thesis.

- Feedback. Several students express a wish for more feedback on assignments, and point out that feedback is important even if you score a high grade. The students are keen to perform well in their studies and feel that feedback from teaching personnel is crucial in this regard. In cases where students have received feedback on their assignments, they greatly appreciate it and feel that it has played an important role in their academic development.

"When I think about it now, it is incredible; for the past 11/2 years, a professor from one of the partner universities has written personal feedback to me on my assignments." - Nordic NMP student 


\section{Life as an NMP student}

In this section, the students were asked to describe their relationship to the NMP. Students were also asked to rate the student services at their place of study and to assess how they had influenced their experience of the NMP.

\section{Identification}

- Identification as a NMP student. Asked whether they mainly identify themselves as NMP students or students at one of the partner institutions, all but one of the interviewees state that they identify themselves as NMP students, at least to some degree, with many even identifying themselves primarily as NMP students. Those students who do not primarily identify themselves as NMP students state that they identify themselves primarily as students at the first institution in their NMP programme. This was especially prevalent among exchange students or those who had done their Bachelor's degree at the same institution where they were doing the first year of their NMP. However, these students also say that, as the date on which they'd move to the next country drew closer, their identification as NMP students increased. Students on very small NMPs also identify themselves to a lesser degree as NMP students, since they were merged with a larger group of non-NMP students.

"The only difference between being a Nordic Master student and a local student is the second year. Right now, I don't feel that I am any different from local students, but that might change next year, when I switch to a new location." - European NMP student

Students whose NMP included only a few shorter, intensive courses at other institutions also identify themselves to a lesser degree as NMP students:

"I only experienced the Nordic Master Programme twice during our two intensive courses."

$$
\text { - Non-European NMP student }
$$

Many of the students that most strongly identify themselves as NMP students also mention that, at the beginning of the semester, intensive courses, gatherings or different social activities for all NMP students were very important for shaping the group. These students also had regular meetings or classes with the other NMP students within their programme. Online courses with professors and NMP students from the other partner institutions also seemed to be an effective method of ensuring a strong sense of identity. However, the identification as a NMP student could also be lost if it wasn't maintained at the second university within the NMP:

"In Sweden I identified myself as a NMP student, but in Denmark I am treated as an exchange student just like anyone else." - Non-European NMP student

Some of the students who identify very strongly as NMP students also state that they feel proud of doing the NMP and like to highlight that they are doing a Nordic degree, instead of a national degree.

"I usually preferred to identify my degree as a Nordic degree. There is more honour in doing a degree that involves six other Nordic universities." - Non-European NMP student 


\section{Student services}

When discussing student services, many of the issues raised by the students are connected to their first weeks at a new campus. It is clear from the interviews that the students value the introduction programmes. When no shared NMP introduction was given, it was missed. The most commonly mentioned practical issues relate to difficulties in finding accommodation, which many students had found especially challenging. The most important student services mentioned are:

- Welcome programme. As mentioned above, a co-ordinated welcome for NMP students is seen as very important in establishing an NMP identity. Several students also compliment the arrangements made for them in the form of welcome packages containing information on practical issues, as well as local student tutors who help them get started in their daily lives both on and off campus. Some students even say that these services should be highlighted when applying for the programme, since it would perhaps make the whole process of moving from one country to the other seem less intimidating and encourage students to apply for the NMP. In cases where this type of support has not been available, some of the interviewees describe their first weeks of the NMP as chaotic and turbulent.

- Support of other NMP students. Several of the interviewees express a wish for stronger support from NMP students doing their second year on the programme. In some cases, the second-year students provided support on their own initiative. This support is highly valued by the new students, who feel that older students from the same programme have been able to help them with both practical and academic guidance. Contact with other NMP students is also mentioned by students who have not had access to such a network. They express a clear wish for stronger knowledge-sharing within a larger network of NMP students, especially related to practical issues such as finding accommodation or organising social activities. This type of a network within the NMP programmes (or even including all NMP programmes) could be especially useful during the transition from one country to another. As described by one of the students:

"Next year I don't know anyone in Finland, so it would be better if I know someone there already. Some co-ordination between the Nordic Master Programmes would be very good." - European NMP student

- Help with finding accommodation. Of all of the practical issues related to the NMP, finding accommodation is clearly the most challenging. While some of the interviewees have received help from their NMP institutions in securing accommodation, several have had to resolve the issue on their own. In many cases, this has been a very time-consuming and difficult process, especially if the student has received information about their acceptance to the programme only shortly before the move. High accommodation costs combined with a lack of housing, particularly in bigger cities like Stockholm, have been especially challenging. It has not been uncommon for some NMP students to find themselves without a place to stay at the start of the semester. Some students also mention that they had initially been promised assistance in finding accommodation, but when this help was not provided it made them question the quality of the NMP as a whole.

Another issue worth mentioning, one related specifically to the NMP and student housing, has occurred on programmes where students stay at one university for the full two years, but are free to do online courses with any of the partner universities. In these cases, students have been forced to move out of their student apartments after the first year, since they were no longer completing enough 
credits at the university where they were based, despite the fact that they were completing online courses with the other NMP-partner universities.

- Integration into local culture. Several of the interviewees express a wish for stronger interaction with local students and greater familiarity with the Nordic way of life. Some report that getting involved in student organisations has been a way of meeting local students, but in many cases it seems that the international NMP students mainly engage in social activities with other international students, even though many of them express a clear desire for more integration into the local culture.

"I am not abroad only for the studies, I want to learn about the culture, too."

$$
\text { - Non-European NMP student }
$$

- Leisure activities and health care. All in all, the NMP students seem to have good access to general student services such as health care, sports and other leisure activities. These issues are not highlighted as problematic during the interviews. When they are mentioned, it is more a matter-of-fact statement of the existence of these services. In other words, there do not seem to be any issues related to this area. 


\section{Mobility and finances}

The NMP programmes are characterised by very varying levels of mobility. Students were asked to describe their experiences and to evaluate what level of mobility compensation/grant would be appropriate for students doing the NMP.

- Degree of mobility. The existing NMP programmes are all designed in different ways, but they can still be divided into two main categories when it comes to mobility: 1) programmes that arrange their mobility through shorter, intensive courses; and 2) programmes that include longer periods of mobility, with the students living in two or more Nordic countries.

Intensive courses. Of the 14 students interviewed, six were or had been enrolled in NMPs with shorter mobility periods lasting from four days up to three weeks at a time. ${ }^{1}$ The number of mobility periods also varied between the programmes, from only two weeks during the entire NMP to up to a total of six intensive courses (each lasting four or five days) during the course of two years.

Longer mobility periods. Of the students interviewed, eight were or had been enrolled in NMPs with longer mobility periods lasting at least three months each. While there is some variation between programmes, it seems as if most long-term mobility arrangements are built on the 1+1 model, where students study for one year in one Nordic country and the next year in another. However, there are NMPs where students change locations after the first semester, as well as programmes where the 1+1 model is complemented with additional intensive courses, which in some cases gives students the opportunity to experience up to four different locations.

- Opinions of mobility. The students were asked to evaluate how satisfied they were with the mobility offered to them, and to outline what kind of mobility they would have preferred or had been expecting. Generally, students in programmes with longer mobility periods express greater satisfaction with their mobility than students doing only intensive courses, but there are some notable exceptions.

Intensive courses. All of the students who experienced only a few weeks of mobility during their NMP say that they had expected the programmes to contain more mobility. When asked why there had not been more intensive courses, the students cite as potential reasons issues such as lack of resources and the fact that their NMP programmes are very small.

"It's been over a year and so far we've only heard about the chance to visit one partner university (in Sweden). All in all, I'm satisfied, but it would have been even better if there would have been more courses on offer at the other universities, too." - Nordic NMP student

Students also say that they were unclear about how much mobility they could expect from the programme and that there was a lack of information about the different options within the NMP. When choosing the NMP, some students had even expected the mobility to be arranged differently:

\footnotetext{
${ }^{1}$ Includes students from three NMPs: Religious Roots of Europe; Computational Chemistry and Physics; and Gerontology.
} 
"I thought I would go to more countries for longer periods, perhaps even whole semesters in other places" - Non-European NMP student

Many of these students also state that they would have preferred an NMP model with longer mobility periods, since this would have allowed for a deeper experience, both culturally and academically.

Although it is quite clear from the interviews that students expected the NMP to contain more than just one or two shorter mobility periods, students who had taken several shorter mobility periods during the course of two years were very satisfied with the way the mobility had been arranged. In these cases, students had taken up to six shorter, intensive courses at different Nordic institutions over the course of two years. In other words: NMPs located in only one Nordic country can fulfil the student's expectations of mobility through shorter, intensive courses, provided that these occur often and are regularly distributed throughout the programme. These students say that they appreciated the chance to move around and visit different academic environments while still living in only one Nordic country throughout the programme.

"Although I was at the other institutions for only four days at a time, I still felt during those days as if I was a student there." - Nordic NMP student

Longer mobility periods. Students from NMPs with longer mobility periods seem generally very satisfied with the way the mobility had been arranged. In most cases, this involved the $1+1$ model, with students spending one year each at two different Nordic institutions. This is also the model preferred by most of the interviewees (regardless of the type of mobility they themselves have experienced).

Some of the students say that they would have been interested in even more mobility, e.g. six-month stays in different locations. At the same time, students acknowledge that increased mobility requires additional practical arrangements in terms of finding accommodation and getting used to a new living environment. Practical limitations such as visa requirements also play a role for non-European students. Many also say that they feel somewhat reluctant to leave their first place of study, since they have formed such strong social bonds during their first year - a problem that would only be exacerbated with several moves from one country to the other.

"When you study at a new university, you need some time to adjust to the local culture and the teaching system. If you keep moving on every six months, it is very challenging to get adjusted and you can't focus properly on your studies." - Non-European student

"I was quite happy to have the freedom to choose from the course programmes from all the partner universities for the second semester. But if I think about it now, it creates a lot of fluctuation and splits up the whole NMP group after just six months. It could be a good model to have the first full year in one place." - European NMP student

When asked if they would have preferred an NMP in one location but with several intensive courses instead, none of the students doing long-term mobility programmes say that they would have chosen that option. For them, the benefits of experiencing more than one country (even with the associated practical issues) outweigh the downsides: 
"My purpose is to extend my network. By spending just a few weeks in one location you can't accomplish so much." - European NMP student

When it comes to long-term mobility, the strongest criticism among these students (as mentioned in the section on academic guidance) concerns the lack of information when designing their NMPs and choosing their placements. On some programmes, the mobility options also seem to be rather strict, and don't allow the students to change study track during the NMP. This becomes especially problematic in cases where the NMP is combined with other mobility agreements (such as Erasmus exchanges or other bilateral agreements), which may have their own specific requirements.

- Mobility expenses. Students were asked to estimate their mobility expenses (including travel and accommodation during shorter courses) over the entire programme. The sums vary from $€ 200$ to $€ 2000$, depending on the way in which the mobility aspects of the programme had been arranged.

Intensive courses. Students from NMPs with several shorter, intensive courses estimate that their mobility costs (travel and accommodation) have been or will be around $€ 2000$ over the two years. For the interviewees, all expenses were covered by the programme - although in most cases they initially were required to pay for travel themselves and seek reimbursement later. It was stated that the NMP would try to compensate students for expenses incurred (although this could not be guaranteed). The students always participated in the seminars knowing that they might not be compensated for their expenses. In many of the programmes, students were also offered daily allowances of approx. €20 during the intensive courses.

"For me, it was not a problem to purchase the tickets beforehand and get compensated later on, but for students with O EUR in their accounts, this would not have been possible." - Nordic NMP student

Long-term mobility. In comparison to doing several intensive courses, the students who studied in two or more countries for longer periods estimate their travel costs to have been somewhat lower, ranging from $€ 200$ to $€ 800$. However, many of these students point out that they have had additional expenses associated with relocation, which would probably not have arisen had they only lived in one place. With that said, many of the students also state that they had been prepared for the costs and were willing to pay for the experience.

"Economically, it has certainly not been very smart of me, but it is a price I am very willing to pay for all the experiences I have had." - Nordic NMP student

- Mobility grant. Students were also asked to estimate what would be a suitable amount for a grant that would cover the mobility costs of NMP students. Again, the answers vary somewhat depending on the mobility of the programme, but most students estimate that a mobility grant of $€ 200-500$ would cover the expenses of moving from one Nordic country to the other. For daily allowances for shorter mobility periods, students consider $€ 20-30$ to be sufficient.

While the vast majority of those interviewed feel that a guaranteed mobility grant would be very beneficial for the NMP, in one specific case a student points out that that students should be prepared for the additional costs of the NMP and that additional funds could instead be directed towards establishing a stronger network among NMP students: 
"If there are extra resources, they could instead be put into organising more NMP activities and perhaps arranging for all NMP students from all programmes to meet each other." - European NMP student

- General financial situation. When it comes their financial situation, the NMP students are far from homogenous. Students finance their studies from a wide range of different sources: parental support, their own savings, part-time jobs, scholarships, student loans and state-granted allowances. Also, while some students say that their economic realities have not changed at all due to the NMP, others state that they have barely survived the high living costs in the Nordic countries. Some non-European students are also burdened with visa requirements such as bank securities (which can be up to several thousand euros) before they are allowed into the Nordic countries. Several of the interviewees say that some kind of scholarship system for the NMP programme, taking into account the costs of living in the Nordic countries, should be introduced for those students who need it. 


\section{Staying in the Nordic countries}

In the online survey, $82 \%$ of the respondents said they will definitely $(41 \%)$ or possibly $(41 \%)$ stay in the Nordic countries after graduation. Even though it is mainly the Nordic students who know for certain that they will stay, one can still conclude that there is a high level of interest in staying in the Nordic Region even among nonNordic students. This is confirmed in the interviews, where nearly all of the non-Nordic students say that they would like to stay in the Nordic Region. The main reasons for staying are family connections or other personal relations in the Nordic countries. Some students simply say that they have enjoyed their studies and are now keen to experience working life in the Nordic countries.

However, some still feel that they are unlikely to stay. The reasons for not staying are mainly related to a lack of integration into the local community or to not being fluent in the local language. Both personal and professional networks seem to be determining factors for whether a student wants to stay in the Nordic Region or not. Language skills are mentioned as especially important for social integration.

- Personal network. Of the non-Nordic students interviewed, those who express the strongest wish to stay are usually those who have a prior family connection to the Nordic countries or who have forged other significant relationships during their studies. In terms of integration, these students have also often learnt the language, at least to some extent, and feel that they have a large personal network.

Interestingly, since many of the students interviewed aim to continue working within academia, they don't feel that language skills will be a big barrier for them in finding work. Instead, language skills are mainly brought up in relation to social interaction and integration into society. In other words, learning the language seems to be very much connected to becoming a part of the local community.

"I want to learn the language so that I can get into the culture." - European NMP student

"The main problem is the language. If you don't know the language of the country, it is difficult to get to know the people and make friends with them." - Non-European NMP student

In some cases, however, even learning the language does not help with integration:

"I've lived in this country for many years now and I've learnt to speak the language. But still, I'm treated as foreigner. I don't think I will stay." - Non-European NMP student

- Professional network. The students who were most positive about their opportunities in the Nordic countries were those who felt that the NMP had given them a relevant network on which to build. As previously mentioned, the NMP is also highly rated by many because of the professional network it provides for aspiring PhD students. In addition, contacts with industry are described as extremely important for establishing a professional network. Again, language skills are mentioned as a factor, but mainly by students who don't wish to pursue a PhD. 
"Completing this programme is a great advantage when it comes to staying in Denmark. I got to know quite a lot of potential networking partners, and the bonds are strong between the participating institutions. Being a part of this network certainly paves the way to continue [working] in one of these countries."

- European NMP student

"It is not only about having a degree from a Nordic university. Contacts to the industry are also very important." - European NMP-student

Students also express a wish for more career guidance on their post-graduation opportunities. In particular, they are especially keen to get more information on how their NMP is applicable on the labour market. Again, establishing contacts to working life during their programme is identified as a relevant factor:

"I don't know what employers think of the programme, since we have not had any contact with the industry." - Non- European NMP student 


\section{Conclusions}

In general, NMP students feel that the programme has offered them something unique. Mobility is a key factor in the programme being perceived as interesting and in how successful it is determined to be. Mobility-related factors such as experiencing many Nordic countries, gaining access to many high-quality institutions and building a large network all help to make the NMP a more attractive option than national programmes. Nevertheless, some issues still need to be resolved in order to ensure that the NMPs function even better in the future.

In conclusion, as a minimum, the following facts should be acknowledged when discussing the quality of current and future NMP programmes from the students' perspective:

- Different mobility models attract different students; while Nordic students find it somewhat more attractive to stay in one place for the full duration of the programme, in general it is the $1+1$ model that is most popular. Students who have experienced the 1+1 model are also generally more satisfied with their NMP, compared to those students who have experienced several shorter, intensive courses abroad. Clearly, no matter how the mobility is designed, it needs to remain a central part of the NMP for the programme to be deemed successful.

- Currently, the NMPs attract non-Nordic students who are already interested in the Nordic countries. Among Nordic students, the NMPs are mainly marketed to those already studying at the partner institutions. If the NMPs are to grow, the scope of the marketing needs to be broadened beyond these groups.

- $\quad$ Although most of the students seem to be prepared for the NMP to cost more than just studying in one country, many also say that they are struggling with the high costs of living and studying in the Nordic countries. Students are very positive about the idea of a mobility grant that would cover the expense of moving from one country to another.

- $\quad$ Lack of tuition fees is a factor for some students when applying for the programme. If all NMPs charged tuition fees, this group of students would need scholarships in order to participate.

- Since nearly all of the students interviewed have experienced some issues with the administration of the programme, it is clear that closer attention must be paid to administrative details. Otherwise, issues in this area risk overshadowing the overall benefits of the NMP.

- Students have a strong need for guidance in relation to practical issues, especially upon arrival in a new city or country. In particular, help with finding accommodation is crucial.

- Students must be clearly informed about whom they can contact for administrative assistance and academic guidance. This should not necessarily be the same person.

- Second-year NMP students could be more involved in the tutoring of new NMP students, especially in relation to practical issues. Students also express a wish for a network that encompasses all NMP 
programmes, based on the principle that a larger group of NMP students can provide greater mutual support.

- Students also express a wish for stronger academic guidance, especially with regard to the options within the NMP. There is also a need for more information about post-NMP opportunities.

- Many of the students identify themselves strongly as NMP students and are proud of having done the NMP. A high level of NMP identification is strongly associated with the amount of mobility and interaction with other NMP students in the programme.

- Students on smaller NMPs are generally less satisfied than students from larger NMPs. In this context, factors such as lack of peer support, cancelled courses and fewer resources are mentioned as problems. Students from smaller programmes do not identify themselves as strongly as NMP students, either.

- Many of the students have PhD ambitions. A clear PhD path or close links with ongoing research could further increase the attractiveness of the programme. However, even in its current form, students feel that the NMP offers a good grounding for PhD studies, due to the large network students develop through the programme.

- A strong connection to industry (or working life in general) is attractive for the students, and many express a wish for the NMPs to include some work experience. This could also facilitate staying in the Nordic countries after graduation.

- Students want to become integrated into the local culture, learn the language and - in many cases even stay in the Nordic countries after graduation.

- At best, the NMPs allow students to establish strong professional networks. These networks, together with aspects related to personal integration, are key factors when the students decide whether to stay in the Nordic countries or not. 


\section{APPENDIX 1: Results from Nordic Master Student workshops}

In late August 2012 all current and previous Nordic Master Students were invited to attend workshops for discussing the results of the online NMP student survey and the interviews. The invitations were distributed through the coordinators and directly to those students who had expressed in the survey an interest in participating in further interviews. Four separate workshops were held during September-October 2012 in Copenhagen, Bergen, Stockholm and Helsinki.

In the workshops the results of the survey and the interviews were presented. Students were then asked to discuss all the relevant themes and to highlight which areas they considered to be most important for a successful Nordic Master Programme. Students were asked to focus on practical ways of improving the NMP.

\section{Workshop 1: Copenhagen, $13^{\text {th }}$ September 2012}

In the Copenhagen workshop a total number of seven Nordic Master Students participated, two of which also had participated in the interviews. Students from the following programmes were present: Innovative Sustainable Energy Engineering, Marine Ecosystems and Climate, Religious Roots of Europe, as well as the new programme Viking and Medieval Norse studies.

The participating students agreed that the Nordic Master programme was an exciting opportunity and a chance to do a more internationally orientated degree. When discussing the conclusions from the survey and the interviews, the students noted that (in some programmes) there are already several non-Nordic students without any previous connection to the Nordic countries. This could mean that although a previous connection to the Nordic countries seems currently to be an important factor when choosing the NMP, it might become less important when the programmes become more well-known internationally.

In the Copenhagen workshop students highlighted especially the need for the Nordic countries (and universities) to offer equal opportunities when it comes to access to scholarships and other ways for funding the NMP. Another priority area is the need stronger academic guidance and information on the different options within the consortium. Other topics that were ranked as especially important were research opportunities, relevant work experience and housing. The students also stated that all programmes should be free to design their mobility as most fitting for the field.

All measures that were mentioned:

- Programmes should have the freedom to choose whichever mobility model they prefer. Relevance for the field is the most important factor.

- Intensive courses abroad should always have some country specific content.

- Students should have greater freedom in designing the NMP

- The programmes should offer clear information on the mobility costs.

- Short-term mobility should always be compensated for.

- Students should have equal access to scholarships when funding the NMP. 
- Housing is critical.

- Students need more support and academic guidance in designing the NMP.

- There needs to be a clear coordinator for the NMP and the coordinators need to have time to focus on running the NMP.

- Academic and practical guidance should not come from the same person.

- A NMP fellowship and contact to old NMP students is important. Information from old to new students can be passed on also online through social media and blogs.

- Alumni students can also be used as ambassadors when marketing the programme.

- The programmes need more quality control in order to insure coherence within the consortium.

- E-learning can work, but it needs support.

- Relevant work experience would be valuable, for example through optional built-in traineeships.

- Research opportunities should be included already during the NMP.

- The NMP as a product is good, but it needs to be made more visible - also within the Nordic countries

\section{Workshop 2: Bergen, $17^{\text {th }}$ September 2012}

In the Bergen workshop a total number of eight Nordic Master Students participated, two of which also had participated in the interviews. Students from the following programmes were present: Innovative Sustainable Energy Engineering, Marine Ecosystems and Climate, Religious Roots of Europe, as well as the new programme Environmental Engineering.

Generally, the students agreed with the conclusions of the survey and the interviews. The students complimented especially the NMP for its high level of academic and cultural exchange and the chance to for Nordic students to be international at home. When asked to point out specific priority areas NMPs should focus on, the students agreed that the absolutely most important thing for a working NMP is to have "A unified source of information. Someone who knows of the NMP as a whole and has time" - that is, a coordinator to turn to in all matters related to the NMP. Students were also keen to agree with the conclusion from the interviews, that the academic counselor and the programme coordinator should not be the same person. Other priority areas that were brought up was the need for a network of old and new NMP students, work experience as well as the need to keep the NMP free from tuition fees. The students also noted that many of the current programmes seem to suffer from a lack of commitment from the universities.

All measures that were mentioned:

- No tuition fees

- More information on funding and part-time jobs

- One programme coordinator

- Split academic and administrative guidance

- More information on the possibilities within the programme

- A network for all NMP students (from all programmes) 
- Increase the level of commitment from the university to the NMP

- Improve the communication between the partner universities

- Improve common academic standards between the partner universities (grading, course requirements, etc)

- Create a stronger feeling of a common programme

- All courses should be in English

- Include internships and excursions to companies or other relevant institutions working in the field

\section{Workshop 3: Stockholm, $28^{\text {th }}$ September 2012}

In the Stockholm workshop a total number of twelve Nordic Master Students participated. None of the students had previously participated in the interviews. Students from the following programmes were present: Innovative Sustainable Energy Engineering, Gerontology, as well as students from the two new programmes Environmental Engineering and Sustainable Energy Transitions.

The need for information on all aspects within the NMP was especially evident in the Stockholm workshop. This may be due to the fact that the workshop consisted mainly of first-year students, but it is also obvious from the other workshops that a programme like the Nordic Master has an extreme information need, related to both practical and academic questions. The need for one clear coordinator was mentioned by several students as the most important thing. Assistance with finding accommodation and information on different scholarship opportunities as well as more contact to industry were also highlighted by the students. The students also expressed their concerns regarding "double tuition", since they recently had been informed that they most likely should pay full tuition to both Denmark and Sweden during their two-year NMP, even during the year they would spend in the other country.

All measures that were mentioned:

- More information on all matters

- A nice website

- A clear tuition agreement

- One common coordinator

- More meetings within the programme

- Help with finding accommodation

- Scholarships to students

- Interaction with industry

- Internships / summer courses

- More language courses

- Offer unique courses with specialisation opportunities

Workshop 4: Helsinki $1^{\text {st }}$ October 2012 
The participants in the Helsinki workshop included five students and two local programme coordinators. Students from the following programmes were present: Gerontology, Religious Roots of Europe and Maritime Engineering.

The students expressed a high general satisfaction with the programme, saying that the NMP had been a unique opportunity within their field and a chance to meet students from all over the world. When discussing the most important features of a successful programme, the participants highlighted the need for a broad perspective when designing the NMP: A successful programme consists of several different components and is not only limited to academic content, although high academic is extremely important as the basis for all programmes. It is also important to consider what makes the NMP special in comparison to other international Master programmes. The participants also agreed that adequate career planning guidance should be a part of all NMPs.

All measures that were mentioned:

- Need for a broad perspective when designing the NMP

- Ensure coordination within the NMP

- Measures to ensure high academic quality

- Adequate career planning opportunities

- Finding the best balance between e-learning and face-to-face lectures

- Continuous contact (including e-learning) between students and teachers

- Include 2-year NMP-students as tutors

- Focus on high-class teaching

- Focus on the content of NMP in comparison to other programmes

- Financial resources to student and teacher mobility

- Make sure the mobility matches the purpose - not too many moves just for the sake of mobility

- Possibility of internships/practical training

\section{CONCLUSIONS}

All four workshops confirmed the results from the student survey and the interviews. The need for a clear programme coordinator and information regarding all aspects of the NMP is a clear message from all four workshops. Another reoccurring theme is the students' strong interest in gaining work experience already during the NMP. The wish for stronger NMP networks among new and old students, as well as clear information on tuition fees and scholarship opportunities are other priority areas that should be remembered when developing future Nordic Master Programmes. 


\section{APPENDIX 2: Interview questionnaire}

\section{INTERVIEW questionnaire}

Background:

- Interviewer explains to the student the reasons for the evaluation of the NMP and how the interview material will be used.

- Interviewer explains to the student the structure of the interview.

The areas are:

- Background information

- Motivation for enrolling in the NMP

- Expectations of the NMP

- Teaching styles \& methods

- Life as a studenta

- Mobility across the Nordic countries

- Use of financial resources

- Career opportunities related to participation in the NMP

Practical matters:

- The student is informed that the interview will be recorded. The student is informed that he or she will have an opportunity to revise the written interview.

- $\quad$ Any questions?

\section{Background}

1. What is your nationality? [Nordic, European, non-European]

a. Home country

2. What and where did you study before you applied for the NMP?

3. You are taking the NMP programme $x x x$

a. Where?

b. What year?

c. In which countries have you studied?

d. In which countries will you be studying?

e. In which NMP institutions have you been enrolled as part of the Nordic Master Programme?

f. When did you enrol in the Nordic Master Programme? 
g. Have you graduated from the NMP? / When will you graduate?

4. Have you studied in a foreign country before?

5. Tuition fees - have you been subjected to tuition fees during your NMP?

\section{Motivation and applying}

6. Where did you hear about the Nordic Master Programme?

7. When you were considering applying, was it easy to find information about the programme? Was it sufficient?

8. How would you evaluate the application process? Was it easy or difficult to access all necessary documentation?

- How did you find the application process?

- How did you find the entry requirements?

- Were they easy to understand?

9. Why did you choose the NMP instead of a national Master's programme with a similar focus? What were your main reasons for applying?

10. Did you also consider another exchange programme, e.g. Erasmus?

11. Why did you want to study in a Nordic country?

12. If the NMP had not been available, would you still have chosen to study in the Nordic countries?

13. How important was the opportunity to receive a $\mathrm{PhD}$ in the Nordic countries?

14. Please suggest ways in which the NMP could enhance its marketing/make information more accessible.

15. If student is from outside the EU:

- How did you find the visa application process?

\section{Quality}

16. Did the marketing of the programme correspond to its actual content?

17. How would you rate:

- the academic standard?

- the English skills of your lecturers?

- the administration of the programmes? 
18. Can you give examples of other areas in which the NMP surpassed or did not live up to expectations?

19. Do you identify yourself as a Nordic Master student?

\section{Teaching styles and methods}

20. What teaching styles and methods have been used during your programme (lectures, guest lecturers, elearning, classroom discussions, etc.)?

21. How satisfied are you/were you with the teaching styles and methods used in your Nordic Master Programme?

(For graduates: please answer these questions as though you were still a student.)

22. Please share any comments and/or suggestions you may have for improving the Nordic Master Programme's teaching styles and methods.

\section{Life as student}

23. Upon arrival at your first NMP university, how were you received? Describe the first week of your programme (was anyone there to meet you, guide you through the campus, help you find an apartment, introduce you to other students, etc?).

24. What kind of services have you been offered as a student (e.g. health care, leisure activities, student housing etc.)?

25. Have you been satisfied with these services?

26. Did you experience any problems with your accommodation?

27. How important have these services been for you achieving success in your studies?

28. Has there been enough student interaction, i.e. meeting students from other countries? Mainly NMP students, nationals or other internationals?

29. Is there anything that has worked particularly well/has not worked at all?

30. Please offer suggestions for improving the wellbeing of NMP students.

\section{Mobility}

31. When it comes to mobility, has the NMP lived up to your expectations?

32. To what degree would you have been interested in an NMP taught in only one Nordic country with guest lecturers from other Nordic countries? 
33. Regarding moving from one Nordic country to the other - what has been easy, what has been difficult (living expenses, language, finding accommodation, lack of funding, visa, lack of information, differences in tuition fees)?

34. Which initiatives could have been taken to enhance mobility on your NMP?

(Please give details.)

\section{Economy}

35. Estimate your monthly living costs (rent + food + necessities)

36. Estimate your travel costs:

a. from your home to your first NMP place of study

b. between NMP locations

c. for occasional travel home (how often?)

37. How do/did you finance your NMP studies?

38. Has your home country supported you in any way (scholarship, student allowance, etc.)?

39. Do/did you have enough funds to cover your mobility during your NMP?

40. If there were an NMP mobility scholarship to cover parts of the travel costs, what amount would be reasonable, in your opinion?

41. Has the economic situation been exceptionally hard during your NMP studies compared to your previous studies?

\section{Employment during studies}

42. Did you / do you work for an employer based in a Nordic country with relevance to your studies during your NMP?

43. Is it/would it be beneficial for you to work for an employer based in a Nordic country with relevance to your studies during your NMP?

44. Could anything have been /be done to improve your life as a NMP student?

(Please give details.)

\section{Career}

45. After graduation, in what field do you hope to work?

46. Do you find the Nordic Master Programme to be relevant/beneficial to your future career?

47. Do you plan on staying in the Nordic countries after graduation? 
48. Has your participation in the NMP increased your interest in finding a job in a Nordic country? (For Nordic students: a Nordic country other than your own?)

\section{View from employers}

49. Have you encountered any problems regarding the recognition of your NMP degree?

\section{Recommendation}

50. All in all, how satisfied are you with the Nordic Master Programme?

51. Would you participate in the NMP if you could make the decision again today?

52. Would you recommend the NMP to others?

53. If you have further comments or recommendations regarding the NMP, please elaborate here.

54. If you had to pay tuition fees, would you still choose the NMP?

\section{End}

55. Anything else you would like to add? 